\title{
MONOTONE MAPS ON DIAGONALIZABLE MATRICES
}

\author{
Mikhail A. Efimov And Alexander E. Guterman
}

\begin{abstract}
We characterize injective maps preserving $\stackrel{\#}{*}$-order and maps strongly preserving \&-order on the set of diagonalizable matrices.
\end{abstract}

Mathematics subject classification (2010): 15A86, 15A04, 15A09.

Keywords and phrases: Monotone matrix transformations, sharp partial order, group inverse.

\section{REFERENCES}

[1] A. Alieva, A. Guterman, Monotone linear transformations on matrices are invertible, Comm. in Algebra, 33 (2005), 3335-3352.

[2] A. Ben-Israel, T. Greville, Generalized Inverses: Theory and Applications, New York: John Wiley and Sons, 1974.

[3] I. I. Bogdanov, A. E. Guterman, Monotone matrix maps defined by the group inverse and simultaneous diagonalizability, Matematicheskii Sbornik, 198, 1 (2007), 3-20 [in Russian].

[4] J. DE PILLIS, Linear transformations which preserve Hermitian and positive semidefinite operators, Pacific J. of Math., 23 (1967), 129-137.

[5] G. Dolinar, A. Guterman, J. Marovt, Automorphisms of $K(H)$ with respect to the star partial order, Operators and Matrices, 7, 1 (2013), 225-239.

[6] G. Dolinar, J. Marovt, Star partial order on B(H), Linear Algebra Appl., 434 (2011), 319-326.

[7] M. A. EFIMOv, Additive matrix maps that are monotone with respect to the orders induced by group inverse, Fundamentalnaya i Prikladnaya Matematika, 17, 6 (2011/2012), 23-40 [in Russian], Translated by Journal of Mathematical Sciences (New-York), 193, 5 (2013), 659-670.

[8] M. A. EFIMOV, Linear matrix transformations that are monotone with respect to the $\stackrel{\sharp}{\leqslant}-$ or $\stackrel{c n}{\leqslant}$-order, Fundamentalnaya I Prikladnaya Matematika, 13, 4 (2007), 53-66 [in Russian]. Translated by Journal of Mathematical Sciences (New-York), 155, 6 (1008), 830-838.

[9] M. A. EFimov, A. E. Guterman, Monotone maps on index one matrices, Zapiski POMI, 405 (2012), 67-96 [in Russian], Translated by Journal of Mathematical Sciences (New-York), 191, 1 (2013), 36-51.

[10] M. H. Englefield, The commuting inverses of a square matrix, Proc. Cambridge Philos. Soc., 62 (1966), 667-671.

[11] I. ERdelyi, On the matrix equation $A x=\lambda B x$, Journal of Math. Anal. and Appl., 17 (1967), 117-132.

[12] C.-A. FAURE, An elementary proof of the fundamental theorem of projective geometry, Geom. Dedicata, 90 (2002) 145-151.

[13] A. Guterman, Linear preservers for Drazin star partial order, Comm. in Algebra, 29, 9 (2001), 3905-3917.

[14] A. Guterman, Linear preservers for matrix inequalities and partial orderings, Linear Algebra Appl., 331, 1-3 (2001) 75-87.

[15] R. E. HARTwig, How to partially order regular elements, Math. Japonica, 25, 1 (1980), 1-13.

[16] R. E. Hartwig, S. K. Mitra, Partial orders based on outer inverses, Linear Algebra Appl., 176 (1982), 3-20.

[17] P. LEGIŠA, Automorphisms of $M_{n}$, partially ordered by rank subtractivity ordering, Linear Algebra Appl., 389 (2004), 147-158. 
[18] P. LEGIŠA, Automorphisms of $M_{n}$, partially ordered by the star order, Linear and Mult. Algebra., 54, 3 (2006), 157-188.

[19] S. K. Mitra, A new class of g-inverse of square matrices, Sankhyā, Ser. A, 30 (1963), 323-330.

[20] S. K. Mitra, On group inverses and the sharp order, Linear Algebra Appl., 92 (1987), 17-37.

[21] S. K. Mitra, P. Bhimas AnKaram, S. B. MaliK, Matrix partial orders, shorted operators and applications, London: Word Scientific, 2010.

[22] K. S. S. NAmBooriPAD, The natural partial order on a regular semigroup, Proceedings of the Edinburgh Math. Soc., 23 (1980), 249-260.

[23] P. G. Ovchinnikov, Automorphisms of the poset of skew projections, J. of Functional Analysis, 115 (1993), 184-189.

[24] C. R. RaO, S. K. Mitra, Generalized Inverse of Matrices and its Applications, New York: Wiley, 1971.

[25] P. Robert, On the group-inverse of a linear transformation, Journal of Math. Anal. and Appl., 22 (1968), 658-669.

[26] P. ŠEMRL, Non-linear commutativity preserving maps, Acta Sci. Math. (Szeged), 71 (2005), 781-819.

[27] P. ŠEMRL, Order-preserving maps on the poset of idempotent matrices, Acta Sci. Math. (Szeged), 69 (2003), 481-490. 